\title{
Xenograft Enriched with Autologous Bone Marrow in Inlay Reconstructions: A Tomographic and Histomorphometric Study in Rabbit Calvaria
}

\author{
Marcelo de Oliveira e Silva, ${ }^{1}$ André Antonio Pelegrine, ${ }^{1}$ Alexandre Alves Pinheiro da Silva, ${ }^{1}$ \\ Luiz Roberto Manhães Júnior, ${ }^{2}$ Rafael de Mello e Oliveira, ${ }^{1}$ Silvana Gaiba França, ${ }^{1}$ \\ Antonio Carlos Aloise, ${ }^{1}$ and Lydia Masako Ferreira ${ }^{1}$ \\ ${ }^{1}$ Medicine School, Unifesp, Rua Pedro de Toledo, 781-11 andar, 04039-032 São Paulo, SP, Brazil \\ ${ }^{2}$ Unesp Dental School, 04039-032 São José dos Campos, SP, Brazil \\ Correspondence should be addressed to Lydia Masako Ferreira, lydiamferreira@gmail.com
}

Received 8 May 2012; Accepted 23 July 2012

Academic Editor: Gissur Örlygsson

Copyright (C) 2012 Marcelo de Oliveira e Silva et al. This is an open access article distributed under the Creative Commons Attribution License, which permits unrestricted use, distribution, and reproduction in any medium, provided the original work is properly cited.

\begin{abstract}
Objective. The aim of this study was to evaluate the bone healing after the usage of a scaffold enriched with bone marrow. Study Design. Ten rabbits were divided into 2 groups of 5 animals. Bilateral $12 \mathrm{~mm}$ diameter defects were created in the parietal bones. In control group Bio-Oss were inserted in both defects and, in experimental group, Bio-Oss enriched with autologous bone marrow were inserted in both defects. In these two groups, one of the calvarial defects was covered with Bio-Gide. The rabbits were sacrified 8 weeks after surgery and both CT and histomorphometric analysis were done. Results. The CT showed a lower remaining defect area in the experimental group covered with Bio-Gide when compared with control group, with and without Bio-Gide. The histomorphometrics showed no difference between groups regarding the non-vital mineralized tissue area. For vital mineralized tissue area, the experimental group covered with Bio-Gide obtained a higher percentage area when compared with control group, with and without Bio-Gide. For non-mineralized tissue area, the experimental group covered with Bio-Gide obtained a lower percentage area when compared with control group, with and without Bio-Gide. Conclusion. Both autologous bone marrow and membrane can contribute to the enhancement of bone healing.
\end{abstract}

\section{Introduction}

Bone defects are created by different etiological factors, such as tumors, infections, and trauma. They can usually be treated with bone grafting procedures. For these situations, the autogenous bone graft is considered the gold standard $[1,2]$ because it has osteogenic potential [3]. However, the removal of autologous graft often presents a significant risk of postoperatively complications and morbidity [4].

A large number of bone substitute materials such as homologous, xenogeneic, and synthetic grafts are available, but also have drawbacks related to mechanical and biological properties [5].

Tissue engineering has advanced recently in an attempt to reproduce lost tissues and organs, including bone tissue.
Thus, several studies have been directed to the creation of cellular therapies protocols $[6-8]$ in order to restore the native tissue without requiring the harvest of large autologous bone grafts.

The use of stem cells has been extensively related. Its ability to differentiate into a variety of specialized cells (producing adipose tissue, bone, cartilage, and endothelium) becomes the object of great interest in the tissue engineering field. Many studies have been reported in the literature using mesenchymal cells from bone marrow to maximize the results of bone repair [9-13]. This therapy promotes the use of a vital bone graft, with osteogenic potential, without the need of harvesting an autologous bone graft.

In order to increase the number of available osteoprogenitor cells, mesenchymal stem cells can undergo a series 


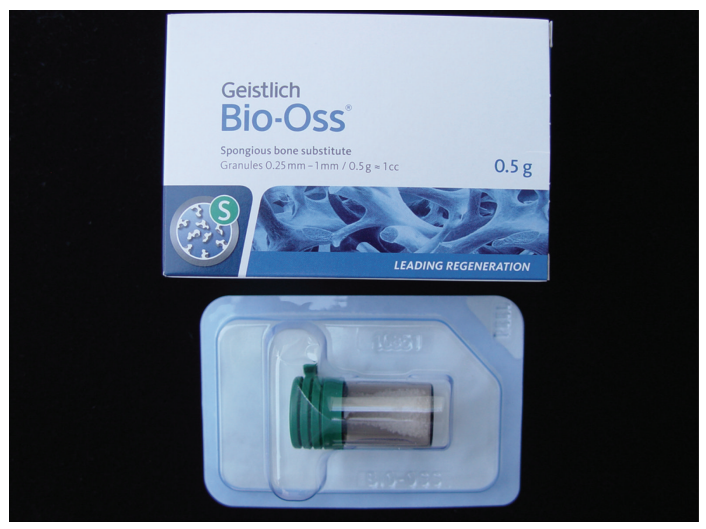

FIGURE 1: Xenograft (bovine origin) with small granules used in the study.

of processes, such as culture [14, 15], concentration [16], and/or incorporation into scaffolds $[17,18]$ before being deployed to the sites to be repaired. However, the role of mesenchymal stem cells is not limited to increasing the number of osteogenic cells. These cells also exhibit angiogenic effects in vivo and secrete sufficient amounts of vascular endothelial growth factor to promote angiogenesis when transplanted transplanted [19].

Despite the possible use of such processes to increase the available mesenchymal stem cells, Pelegrine et al. (2010) [12] have demonstrated good clinical results in bone repair in humans when using the autologous bone marrow without processing it. However, bone healing after the use of the autologous bone marrow incorporated into Bio-Oss, like a scaffold, was never been studied.

Therefore, the aim of this study was to evaluate the percentage of new bone formation, connective tissue, and residual graft particles with bone marrow therapy associated with Bio-Oss, with or without Bio-Gide, in inlay grafts.

\section{Materials and Methods}

2.1. Materials. Bio-Gide (Geistlich Biomaterials, Wolhusen, Switzerland) is a resorbable bilaminar collagen membrane of porcine origin (Figure 1) used to prevent unwanted invasion of adjacent tissues to the bone defect, thus optimizing bone healing [20].

Bio-Oss (Geistlich Biomaterials, Wolhusen, Switzerland) is a particulated xenograft bone substitute [21]. In the present study, it was used as small particles, with granules ranging from $0.25 \mathrm{~mm}$ to $1 \mathrm{~mm}$ (Figure 2).

2.2. Experimental Design. Ten adult, skeletally mature New Zeland white rabbits, weighing $3.5-4 \mathrm{~kg}$ from the animal colony of UNIFESP (Cedeme, São Paulo, Brazil), were used in this study. The animals underwent a period of adaptation to environmental conditions prior to being housed on the premises of UNIFESP. Rooms with controlled temperature 18 to $20^{\circ} \mathrm{C}$ and specific individual cages for rabbits were used. The animals received food based on commercial feed pellets

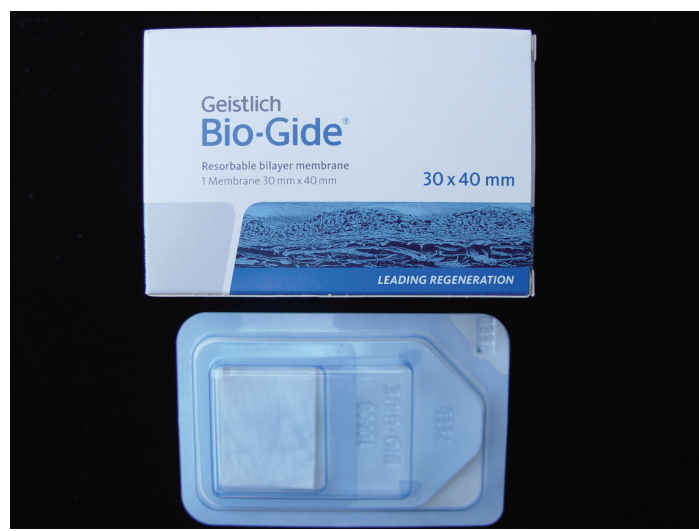

FIGURE 2: Xenogenous (porcine origin) barrier membrane used in the study.

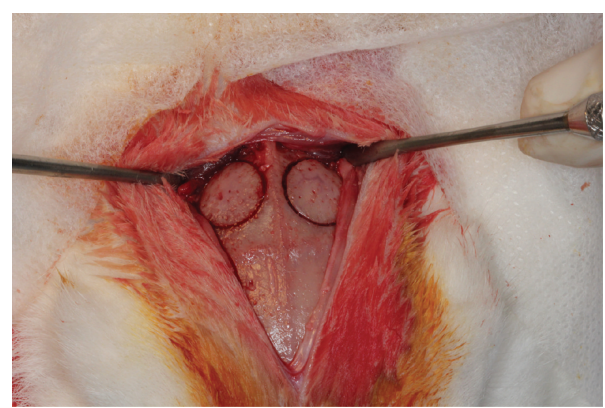

(a)

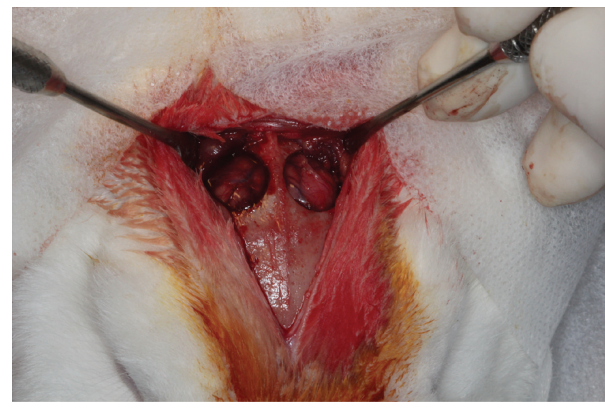

(b)

FIgure 3: Critical-size defects in the parietal bones made with a trephine bur. (a) Before removal and (b) after removal.

and water ad libitum. Bilateral $12 \mathrm{~mm}$ diameter critical-size defects were created in the parietal bones of all animals (Figures 3(a) and 3(b)).

The 10 rabbits were randomly divided into two groups, where in control group animals, the bilateral calvarial defects were filled with Bio-Oss and in experimental group, the calvarial defects were filled with Bio-Oss enriched with an autologous bone marrow aspirate (Figure 4).

In each of the 10 animals, one of calvarial defects was randomly protected with Bio-Gide (Figure 5).

The random process was done by the program available at http://www.randomization.com/. 


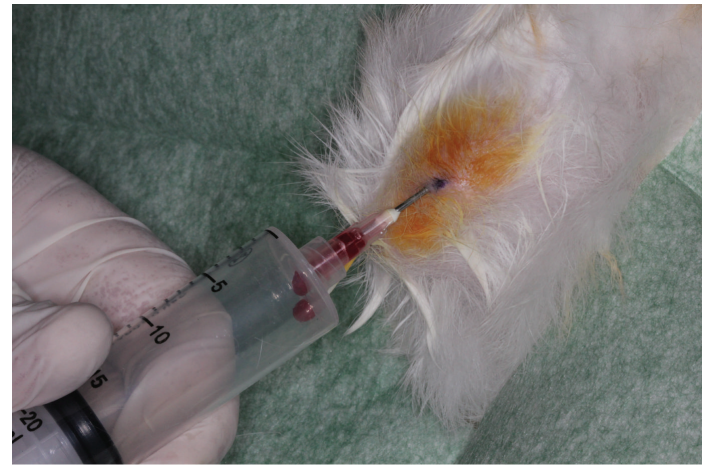

FIGURe 4: Autologous bone marrow being aspirated from the shinbone of one rabbit.

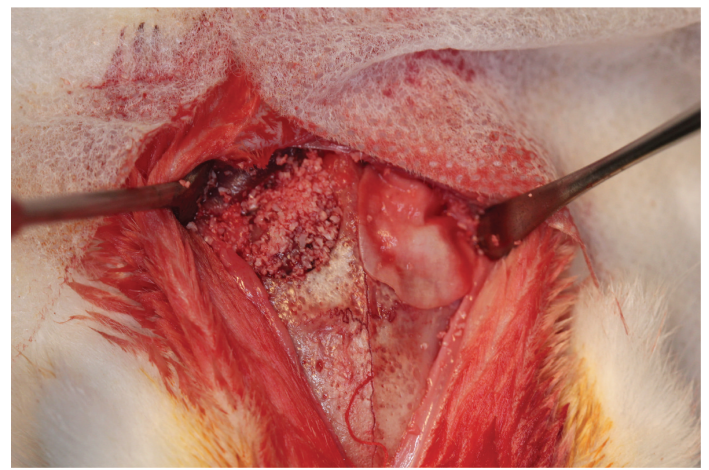

Figure 5: One of the parietal critical-size defects being protected with Bio-Gide membrane.

\subsection{Experimental Steps}

2.3.1. Autologous Bone Marrow Aspiration. Under general anesthesia, bone marrow aspirates were obtained from the shinbone of the 10 rabbits using a disposable $40 \times 10$ needle $(1.10 \mathrm{~mm} \times 38 \mathrm{~mm})$ with $20 \mathrm{~mL}$ disposable syringes embedded with heparin to prevent blood clotting (Figure 2). In the 5 experimental rabbits, the autologous bone marrow was mixed to the xenograft and in the 5 control rabbits, the autologous bone marrow was discarded.

2.3.2. Surgical Protocol. The surgical protocol for this study was analyzed and approved by the Unifesp Ethics Committee (number 2139/2011).

Anesthesia was induced by ketamine $\left(40 \mathrm{mg} \cdot \mathrm{kg}^{-1}\right)$, midazolam $\left(2 \mathrm{mg} \cdot \mathrm{kg}^{-1}\right)$, and fentanyl citrate $(0.8 \mathrm{microg}$. $\mathrm{kg}^{-1}$ ) and maintained using a mixture of $1: 1.5 \%$ isoflurane/ $\mathrm{N}_{2} \mathrm{O}$ : oxygen $(2 / 3: 1: 3)$, using a pediatric-size laryngeal mask airway. The tops of the 10 animals' heads were shaved, and the site was disinfected with a povidone-iodine solution. After administration of a local anesthetic injection of $2 \%$ lidocaine with epinephrine $1: 100,000$, a sagittal incision was made and the skin and periosteum were drawn back.

At this time, the two defects were created, one on each side of the midline, with a $12 \mathrm{~mm}$ diameter trephine bur (Figure 1). The grafts, with or without autologous bone marrow cells aspirate (experimental or control group, resp.), were placed directly onto the dura, replacing the volume of bone that was removed. Then, Bio-Gide membrane was randomly placed over the right or left side in each animal (Figure 5).

In both groups, the incision was closed in layers. Postoperatively, the animals received food and water ad libitum for the remainder of the experimental period.

All 10 animals were sacrified 8 weeks after the initial surgery. Their heads were removed, fixed in $10 \%$ buffered formalin, and scanned with computerized tomography (CT) (Figure 6).

Then, their parietal bones were harvested and decalcified for histologic processing for the histomorphometrics (Figure 7).

\subsection{Auxiliary Services}

2.4.1. Computerized Tomography (CT) Analysis. All CT scans were performed with a Classic i-Cat scanner (Imaging Science International, Haltherfield, EUA). Voxel with $0.25 \mathrm{~mm}$, $8.00 \mathrm{~cm}$ of field view, and $40 \mathrm{~s}$ as an exposure time were selected for all acquisition. The $\mathrm{X}$-rays setting was established by equipment in $120 \mathrm{kV}$ and 5 to $7 \mathrm{~mA}$ in accordance with the resolution. The water was not utilized to simulate a soft tissue because the rabbit's cranium was soaked in $10 \%$ buffered formalin inside a plastic recipient. The rabbit's cranium was positioned in natural way and hugged by wax. A wood support was used to keep the acquisition established.

All the images were processed in Xoran (Xoran Technologies, EUA) software on its own equipment workstation, where any slice anatomic planes correction and bone regeneration analysis were done. Besides the Angio-SharpenMedium $5 \times 5$ filter application in all the images, the contrast, and brightness were also adjusted, in order to give a better image detail for the observer.

The residual defect area, in each side of the rabbit's cranium, was measured in $\mathrm{mm}^{2}$ (Figure 6).

2.4.2. Histologic Preparation and Histomorphometric Analysis. All specimes were decalcified by submersion in 10\% EDTA for 8-12 weeks at room temperature. Each calvaria was further sectioned into an anterior and posterior portion. Both portions were embedded in paraffin blocks. Then $7 \mu \mathrm{m}$ sections of each calvarium were obtained progressively from the middle of the defects, stained with Mallory trichrome, and were qualitatively examined under light microscopy.

Digital images were captured using a CCD digital camera (RT Color; Diagnostic Instruments, Sterling Heights, MI) attached to the light microscope (Magnification X 1.25). To create a single image for each histologic section, the digital images were merged using Adobe Photoshop Elements 2.0 (Adobe Systems, San Jose, CA).

A blinded investigator has traced all the images for new bone formation using Image Pro Plus 4.5 Software for Windows (Media Cybernetics, San Diego, CA). The following parameters were measured: (1) non-vital mineralized tissue (NVMT); (2) vital mineralized tissue (VMT); and (3) nonmineralized tissue (NMT) (Figure 7). 


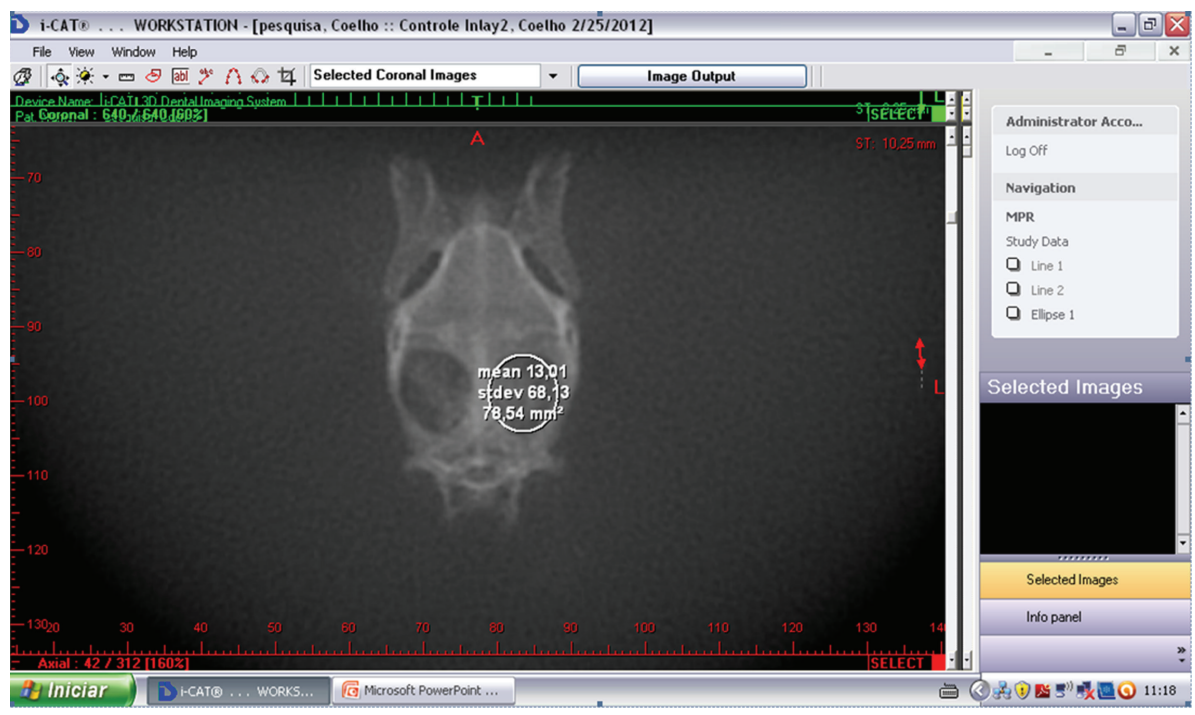

FIGURE 6: CT view after the measurement of a residual defect area.

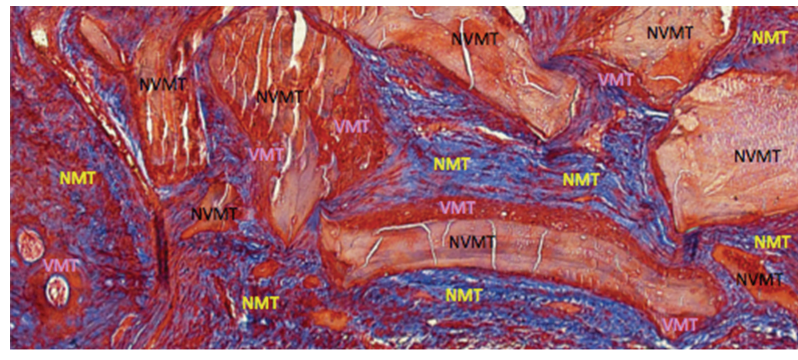

NVMT: Nonvital mineralized tissue

VMT: Vital mineralized tissue

NMT: Nonmineralized tissue

FIgure 7: Histological view of NVMT, VMT, and NMT in 100x magnification (Mallory trichrome).

All results were expressed as a percentage of total area of the defect. Four sections taken posterior and 4 sections taken anterior of the center of the defect were analyzed.

2.4.3. Statistical Analysis. All quantitative data were analyzed with GraphPad Prism (GraphPad Software Inc., San Diego, USA). ANOVA test were used for comparisons between groups, and a $P$ value less than 0.05 indicated statistical significance.

\section{Results}

3.1. Tomographic Results. The CTs analysis showed that the experimental group where the Bio-Gide was used had a statistically significant lower remaining defect area when compared with control group (both with and without BioGide coverage). On the other hand, when comparing both experimental groups (with and without Bio-Gide) and both control groups (with and without Bio-Gide), it was observed no statistically significant difference (Figure 8 and Table 1).

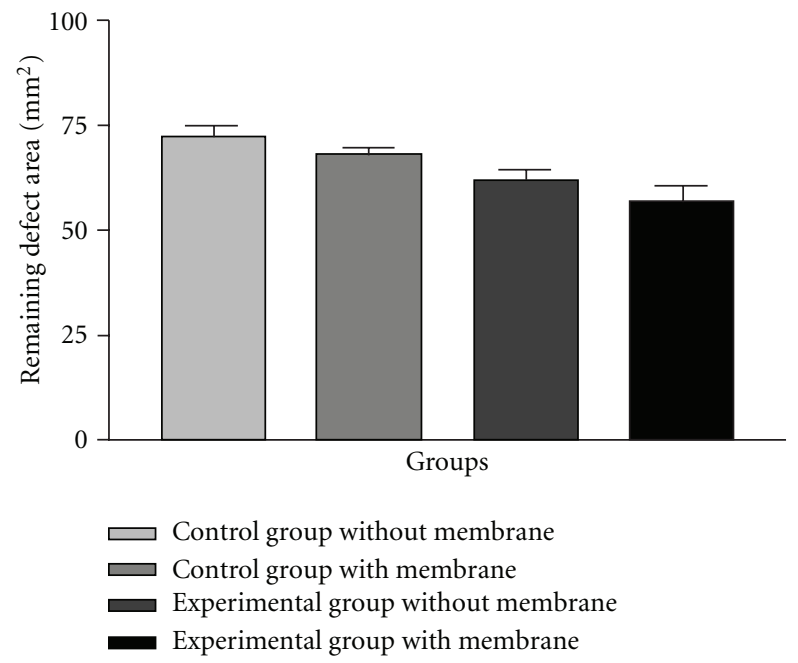

FIGURE 8: Tomographic analysis of the remaining bone defect area (in $\mathrm{mm}^{2}$ ).

3.2. Histomorphometric Results. It was verified statistically significant more new bone formation, with vital mineralized tissue (VMT), in the experimental group where the Bio-Gide was used when compared with the other groups (control groups with and without Bio-Gide and experimental group without Bio-Gide). The VMT of the control group with BioGide was similar to the experimental group without Bio-Gide and, both, in a higher level than the control group without Bio-Gide.

The non-vital mineralized tissue (NVMT) had no statistical difference between all groups.

The non-mineralized tissue (NMT) was less prominent in the experimental group where the Bio-Gide was used when compared with the other groups (control groups with and without Bio-Gide and experimental group without BioGide). The NMT of the control group with Bio-Gide was 
TABLE 1: Statistical comparisons between groups were significant. $P$ values $<0.05$ were marked $(*)$.

\begin{tabular}{lc}
\hline Groups & $\begin{array}{c}P \\
\text { value }\end{array}$ \\
\hline $\begin{array}{l}\text { Control group without membrane versus control group } \\
\text { with membrane }\end{array}$ & 0.17 \\
$\begin{array}{l}\text { Control group without membrane versus experimental } \\
\text { group without membrane }\end{array}$ & 0.15 \\
$\begin{array}{l}\text { Control group without membrane versus experimental } \\
\text { group with membrane }\end{array}$ & $0.03^{*}$ \\
$\begin{array}{l}\text { Control group with membrane versus experimental group } \\
\text { without membrane }\end{array}$ & 0.11 \\
$\begin{array}{l}\text { Control group with membrane versus experimental group } \\
\text { with membrane }\end{array}$ & $0.04^{*}$ \\
$\begin{array}{l}\text { Experimental group without membrane versus } \\
\text { experimental group with membrane }\end{array}$ & $0.04^{*}$ \\
\hline
\end{tabular}

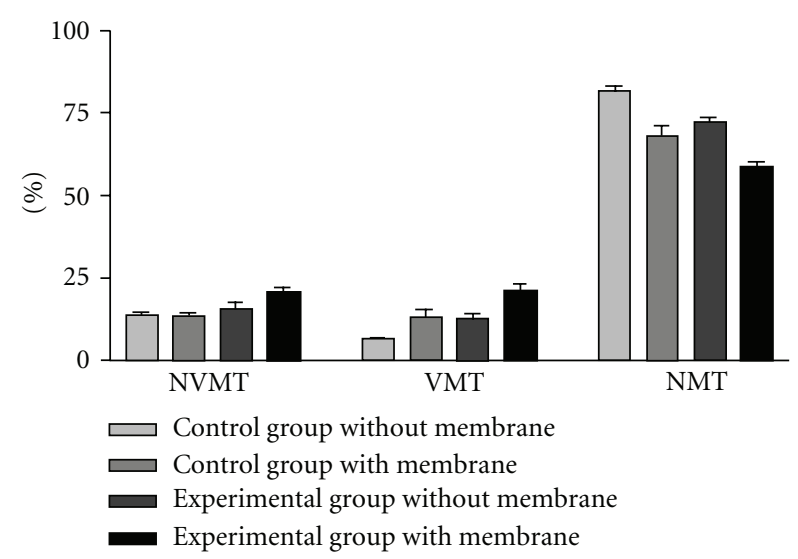

FIGURE 9: Histomorphometric analysis of the non-vital mineralized tissue (NVMT), vital mineralized tissue (VMT), and nonmineralized tissue (NMT) in percentage (\%).

similar to the experimental group without Bio-Gide and, both, in a lower level than the control group without BioGide (Table 2 and Figure 9).

\section{Discussion}

In the present study, critical size defects were created in rabbit calvaria. Critical size defects are those bone defects that cannot completely heal by itself, which was evaluated by Borie et al. (2011) [22] that stated that, in rabbit calvaria, a $8 \mathrm{~mm}$ diameter defect could not regenerate without the use of a bone graft. Despite this affirmation, in the present study, we have used defects of $12 \mathrm{~mm}$, which allowed the attainment of a large defect that could justify the use of a new concept, like the proposed by the incorporation of an autologous bone marrow graft to a xenograft.

The osseoconductor xenograft Bio-Oss was used in both, experimental and control groups. This material is identical to human bone, both from a chemical and physical point of view and can be used to substitute the autologous bone graft in many cases [23-26]. Recently, Sollazzo et al. (2010) [27] reported that Bio-Oss acts in the early differentiation stages of human mesenchymal cells, which could contribute to bone formation. Therefore, the use of Bio-Oss like a scaffold in the tissue engineering field seems to be reasonable.

In the control group, where the Bio-Oss was not associated with autologous bone marrow, both the tomographic and histomorphometric analysis demonstrated a lower bone level when compared to experimental group, where Bio-Oss was associated with autologous bone marrow. These better results achieved in the present study by the use of the autologous bone marrow in inlays defects corroborate Lucarelli et al. (2004) [28], Paley et al. (1986) [29], and Pelegrine et al. (2010) [12]. More recently, tomographic and histomorphometric analysis showed benefits with the adjunct use of autologous bone marrow with homologous bone graft in onlay bone reconstruction in humans, allowing dental implant installation after 6 months [30]. This might be explained by the presence of stem cells in the grafted bone marrow in the experimental group, but there are other factors in bone marrow that could contribute to these better results, such as the presence of other cells and growth factors in bone marrow.

In the present study, the bone marrow was harvested in both groups (control and experimental), despite the effective use of it just in the experimental group. It was done to standardize the rabbits' stress level between groups.

The use of a barrier membrane demonstrated better results. In the experimental group, where Bio-Gide was used, the tomographic analysis showed the lowest level of residual bone defect area. Newly formed bone progressed in a centripetal fashion reducing, consecutively, the partially mineralized central area. By the histomorphometric analysis, it was showed that the use of a barrier membrane, that can exclude the soft tissues in the early bone healing stages like Bio-Gide, increases the amount of vital mineralized tissue (VMT) and decreases the amount of non-mineralized tissue (NMT), both in control and experimental groups, corroborating Busenlechner et al. (2005) [31].

The NVMT represents Bio-Oss residual particles. NVMT occurred in a similar pattern in all groups, showing that, despite the better bone formation with the use of bone marrow and Bio-Gide, the resorption level of the xenograft particles was not altered. This can be considered a benefit in many procedures where the graft resorption rate needs to be slow.

The higher level of vital mineralized tissue (VMT) and the lower level of non-mineralized tissue (NMT) that were obtained with the use of Bio-Gide and autologous bone marrow graft were optimized when both were used together, suggesting a possible synergic effect between them. Therefore, the use of autologous bone marrow seems to have a similar potential of the autogenous bone graft when associated to a bone substitute material, since the inclusion of an appropriate amount of autogenous bone in the grafting material has been reported to substantially shorten the healing time when compared to sites grafted with bone substitutes alone [32].

In rabbits, the bone metabolism is approximately three times faster than in humans [33]. This fact justifies the 
TABLE 2: Mean and standard deviation of the non-vital mineralized tissue (NVMT), vital mineralized tissue (VMT), and non-mineralized tissue (NMT), analyzed by histomorphometrics, in percentage $(\%) . P$ values $<0.05$ were marked $(*)$.

\begin{tabular}{lcccccccccc}
\hline & \multicolumn{2}{c}{$\begin{array}{c}\text { Control group } \\
\text { without membrane }\end{array}$} & \multicolumn{2}{c}{$\begin{array}{c}\text { Control group } \\
\text { with membrane }\end{array}$} & \multicolumn{2}{c}{$\begin{array}{c}\text { Experimental group } \\
\text { without membrane }\end{array}$} & \multicolumn{2}{c}{$\begin{array}{c}\text { Experimental group } \\
\text { with membrane }\end{array}$} & $n$ & $P$ value \\
\hline & Mean & SD & Mean & SD & Mean & SD & Mean & SD & \\
\hline NVMT & 13.64 & 2.34 & 13.35 & 3.13 & 15.31 & 5.22 & 20.29 & 4.17 & 5 \\
VMT & 6.31 & 1.29 & 12.78 & 5.9 & 12.44 & 7.08 & 21.16 & 3.76 & 5 & 0.21 \\
NMT & 81.41 & 3.25 & 67.95 & 7.03 & 72.16 & 3.27 & 58.54 & 3.58 & 5 & $0.01^{*}$ \\
\hline
\end{tabular}

sacrifice of the animals after eight weeks in the present study since bone augmentation procedures are usually performed six months, or 24 weeks, prior to implant placement.

The higher levels of VMT, the lower levels of NMT, and the lower remaining defect area, after 8 weeks, in the sites grafted with the autologous bone marrow associated to the guided bone regeneration technique suggest that the bone healing process is accelerated by this technique and, maybe, the quality of the healing process is maximized. It could allow more accurate bone regeneration and also the placement of a titanium implant after a lower healing time than that used today. However, this hypothesis must be confirmed by further studies with a longer healing period.

Until now, there was no published study analyzing the effectiveness of the association between Bio-Oss, Bio-Gide, and autologous bone marrow graft. Although the present study suggests that the use of autologous bone marrow and Bio-Gide, associated with Bio-Oss, presents higher levels of bone gain after 8 weeks, the potential of other methods of using stem cells such as the use of cultivated bone marrow stromal stem cells and the use of the bone marrow mononuclear fraction still needs to be compared to the presented method in animal models.

\section{Conclusion}

Both autologous bone marrow and the barrier membrane can contribute to the enhancement of bone healing, in a quantitative and qualitative manner, and seem to have a synergic effect when used together.

\section{Disclaimer}

The authors have no relationship with the manufactures listed in this paper.

\section{Acknowledgment}

The authors wish to thank the Geistlich Pharma for donating the xenogeneic biomaterials used in this study.

\section{References}

[1] S. C. Gamradt and J. R. Lieberman, "Bone graft for revision hip arthroplasty: biology and future applications," Clinical Orthopaedics and Related Research, no. 417, pp. 183-194, 2003.

[2] R. Zimmermann, R. Jakubietz, M. Jakubietz et al., "Different preparation methods to obtain platelet components as a source of growth factors for local application," Transfusion, vol. 41, no. 10, pp. 1217-1224, 2001.

[3] W. R. Moore, S. E. Graves, and G. I. Bain, "Synthetic bone graft substitutes," ANZ Journal of Surgery, vol. 71, no. 6, pp. 354361, 2001.

[4] M. Chiapasco, P. Casentini, and M. Zaniboni, "Bone augmentation procedures in implant dentistry," The International Journal of Oral \& Maxillofacial Implants, vol. 24, supplement, pp. 237-259, 2009.

[5] S. E. Duailibi, M. T. Duailibi, W. Zhang, R. Asrican, J. P. Vacanti, and P. C. Yelick, "Bioengineered dental tissues grown in the rat jaw," Journal of Dental Research, vol. 87, no. 8, pp. 745-750, 2008.

[6] B. Johnstone, T. M. Hering, A. I. Caplan, V. M. Goldberg, and J. U. Yoo, "In vitro chondrogenesis of bone marrow-derived mesenchymal progenitor cells," Experimental Cell Research, vol. 238, no. 1, pp. 265-272, 1998.

[7] A. Khojasteh, M. B. Eslaminejad, and H. Nazarian, "Mesenchymal stem cells enhance bone regeneration in rat calvarial critical size defects more than platelete-rich plasma," Oral Surgery, Oral Medicine, Oral Pathology, Oral Radiology and Endodontology, vol. 106, no. 3, pp. 356-362, 2008.

[8] K. Sato, N. Haruyama, Y. Shimizu, J. Hara, and H. Kawamura, "Osteogenesis by gradually expanding the interface between bone surface and periosteum enhanced by bone marrow stem cell administration in rabbits," Oral Surgery, Oral Medicine, Oral Pathology, Oral Radiology and Endodontology, vol. 110, no. 1, pp. 32-40, 2010.

[9] H. Kawaguchi, A. Hirachi, N. Hasegawa et al., "Enhancement of periodontal tissue regeneration by transplantation of bone marrow mesenchymal stem cells," Journal of Periodontology, vol. 75, no. 9, pp. 1281-1287, 2004.

[10] N. Hasegawa, H. Kawaguchi, A. Hirachi et al., "Behavior of transplanted bone marrow-derived mesenchymal stem cells in periodontal defects," Journal of Periodontology, vol. 77, no. 6, pp. 1003-1007, 2006.

[11] F. Pieri, E. Lucarelli, G. Corinaldesi et al., "Effect of mesenchymal stem cells and platelet-rich plasma on the healing of standardized bone defects in the alveolar ridge: a comparative histomorphometric study in minipigs," Journal of Oral and Maxillofacial Surgery, vol. 67, no. 2, pp. 265-272, 2009.

[12] A. A. Pelegrine, C. E. da Costa, M. E. Correa, and J. F. Marques, "Clinical and histomorphometric evaluation of extraction sockets treated with an autologous bone marrow graft," Clinical Oral Implants Research, vol. 21, no. 5, pp. 535-542, 2010.

[13] A. A. Pelegrine, C. E. S. D. Costa, W. R. Sendyk, and A. Gromatzky, "The comparative analysis of homologous fresh frozen bone and autogenous bone graft, associated or not with autogenous bone marrow, in rabbit calvaria: a clinical and histomorphometric study," Cell and Tissue Banking, vol. 12, no. 3, pp. 171-184, 2010. 
[14] N. Kotobuki, M. Hirose, Y. Takakura, and H. Ohgushi, "Cultured autologous human cells for hard tissue regeneration: preparation and characterization of mesenchymal stem cells from bone marrow," Artificial Organs, vol. 28, no. 1, pp. 3339, 2004.

[15] S. Sauerbier, A. Stricker, J. Kuschnierz et al., "In vivo comparison of hard tissue regeneration with human mesenchymal stem cells processed with either the ficoll method or the BMAC method," Tissue Engineering C, vol. 16, no. 2, pp. 215-223, 2010.

[16] Y. Yamada, S. Nakamura, K. Ito et al., "Injectable tissue-engineered bone using autogenous bone marrow-derived stromal cells for maxillary sinus augmentation: clinical application report from a 2-6-year follow-up," Tissue Engineering A, vol. 14, no. 10, pp. 1699-1707, 2008.

[17] S. Sakai, H. Mishima, T. Ishii et al., "Concentration of bone marrow aspirate for osteogenic repair using simple centrifugal methods," Acta Orthopaedica, vol. 79, no. 3, pp. 445-448, 2008.

[18] S. H. Kim, K. H. Kim, B. M. Seo et al., "Alveolar bone regeneration by transplantation of periodontal ligament stem cells and bone marrow stem cells in a canine peri-implant defect model: a pilot study," Journal of Periodontology, vol. 80, no. 11, pp. 1815-1823, 2009.

[19] Y. J. Hwang and J. Y. Choi, "Addition of mesenchymal stem cells to the scaffold of platelet-rich plasma is beneficial for the reduction of the consolidation period in mandibular distraction osteogenesis," Journal of Oral and Maxillofacial Surgery, vol. 68, no. 5, pp. 1112-1124, 2010.

[20] Y. Wu, L. Chen, P. G. Scott, and E. E. Tredget, "Mesenchymal stem cells enhance wound healing through differentiation and angiogenesis," Stem Cells, vol. 25, no. 10, pp. 2648-2659, 2007.

[21] M. M. Bornstein, G. Heynen, D. D. Bosshardt, and D. Buser, "Effect of two bioabsorbable barrier membranes on bone regeneration of standardized defects in calvarial bone: a comparative histomorphometric study in pigs," Journal of Periodontology, vol. 80, no. 8, pp. 1289-1299, 2009.

[22] E. Borie, R. Fuentes, M. del Sol, G. Oporto, and W. Engelke, "The influence of FDBA and autogenous bone particles on regeneration of calvaria defects in the rabbit: a pilot study," Annals of Anatomy, vol. 193, no. 5, pp. 412-417, 2011.

[23] T. Berglundh and J. Lindhe, "Healing around implants placed in bone defects treated with Bio-Oss: an experimental study in the dog," Clinical Oral Implants Research, vol. 8, no. 2, pp. 117-124, 1997.

[24] M. Piattelli, G. A. Favero, A. Scarano, G. Orsini, and A. Piattelli, "Bone reactions to anorganic bovine bone (Bio-Oss) used in sinus augmentation procedures: a histologic long-term report of 20 cases in humans," International Journal of Oral and Maxillofacial Implants, vol. 14, no. 6, pp. 835-840, 1999.

[25] M. Hallman, A. Cederlund, S. Lindskog, S. Lundgren, and L. Sennerby, "A clinical histologic study of bovine hydroxyapatite in combination with autogenous bone and fibrin glue for maxillary sinus floor augmentation: results after 6 to 8 months of healing," Clinical Oral Implants Research, vol. 12, no. 2, pp. 135-143, 2001.

[26] E. S. Tadjoedin, G. L. De Lange, A. L. J. J. Bronckers, D. M. Lyaruu, and E. H. Burger, "Deproteinized cancellous bovine bone (Bio-Oss@) as bone substitute for sinus floor elevation. A retrospective, histomorphometrical study of five cases," Journal of Clinical Periodontology, vol. 30, no. 3, pp. 261-270, 2003.

[27] V. Sollazzo, A. Palmieri, L. Scapoli et al., "Bio-oss acts on stem cells derived from peripheral blood," Oman Medical Journal, vol. 25, no. 1, pp. 26-31, 2010.
[28] E. Lucarelli, D. Donati, A. Cenacchi, and P. M. Fornasari, "Bone reconstruction of large defects using bone marrow derived autologous stem cells," Transfusion and Apheresis Science, vol. 30, no. 2, pp. 169-174, 2004.

[29] D. Paley, M. C. Young, A. M. Wiley, V. L. Fornasier, and R. W. Jackson, "Percutaneous bone marrow grafting of fractures and bony defects: an experimental study in rabbits," Clinical Orthopaedics and Related Research, vol. 208, pp. 300-312, 1986.

[30] C. E. S. Costa, A. A. Pelegrine, D. J. Fagundes, M. J. Simoes, and M. O. Taha, "Use of corticocancellous allogeneic bone blocks impregnated with bone marrow aspirate: a clinical, tomographic, and histomorphometric study," General Dentistry, vol. 59, no. 5, pp. 98-103, 2011.

[31] D. Busenlechner, M. Kantor, S. Tangl et al., "Alveolar ridge augmentation with a prototype trilayer membrane and various bone grafts: a histomorphometric study in baboons," Clinical Oral Implants Research, vol. 16, no. 2, pp. 220-227, 2005.

[32] Y. K. Kim, P. Y. Yun, S. G. Kim, and S. C. Lim, "Analysis of the healing process in sinus bone grafting using various grafting materials," Oral Surgery, Oral Medicine, Oral Pathology, Oral Radiology and Endodontology, vol. 107, no. 2, pp. 204-211, 2009.

[33] W. E. Roberts, P. K. Turley, N. Brezniak, and P. J. Fielder, "Implants: bone physiology and metabolism," CDA Journal California Dental Association, vol. 15, no. 10, pp. 54-61, 1987. 

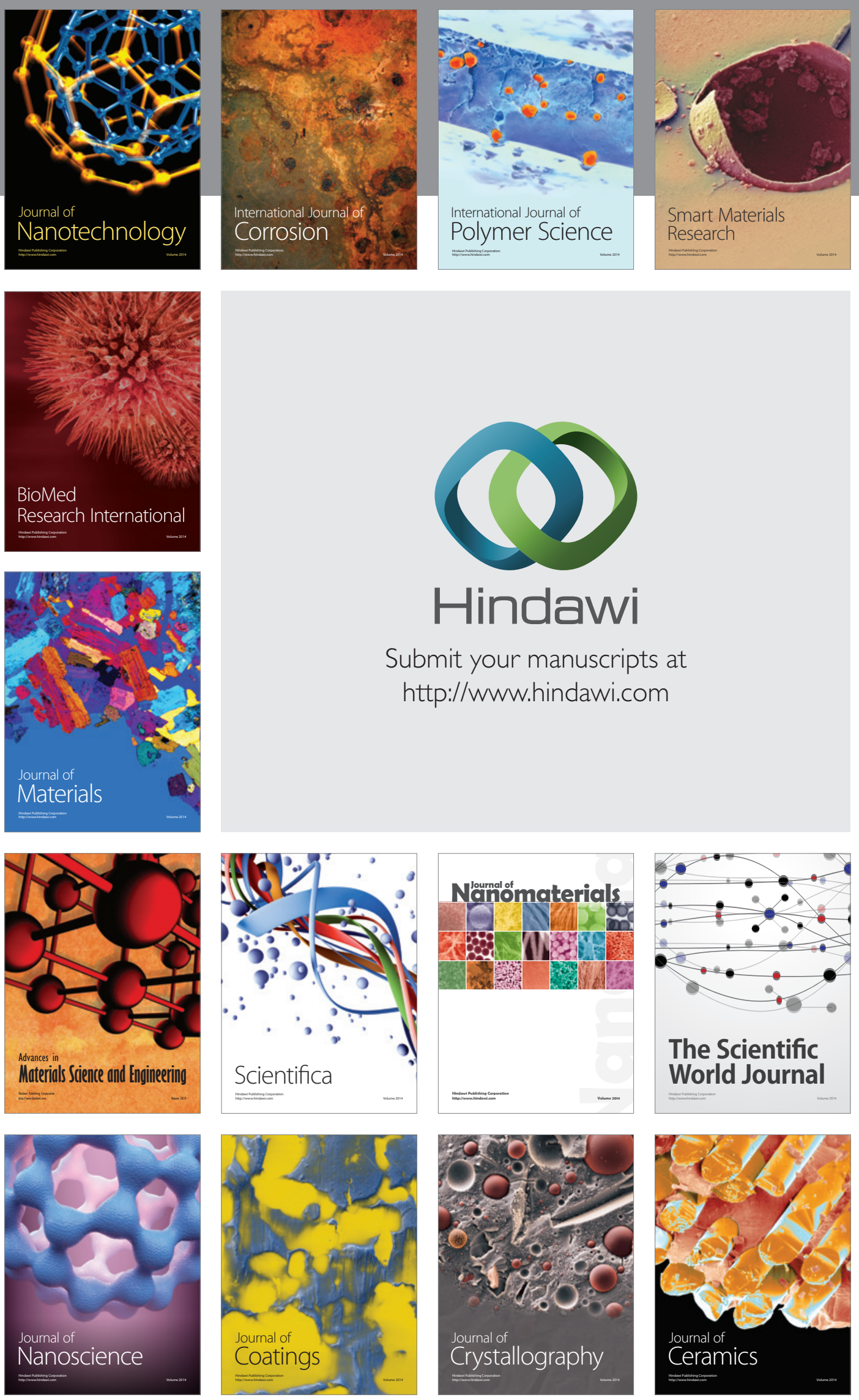

The Scientific World Journal

Submit your manuscripts at

http://www.hindawi.com

\section{World Journal}

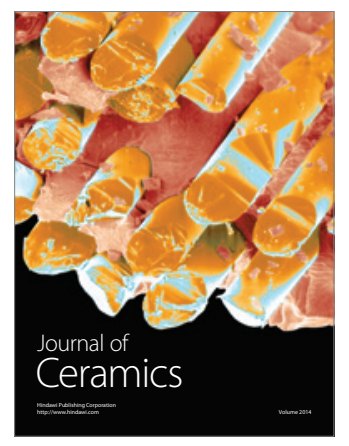

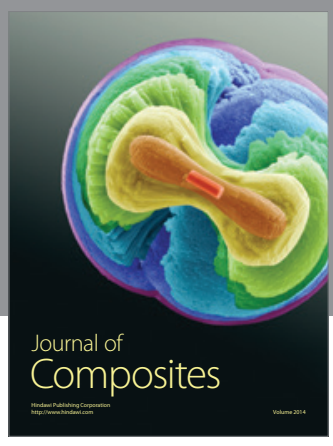
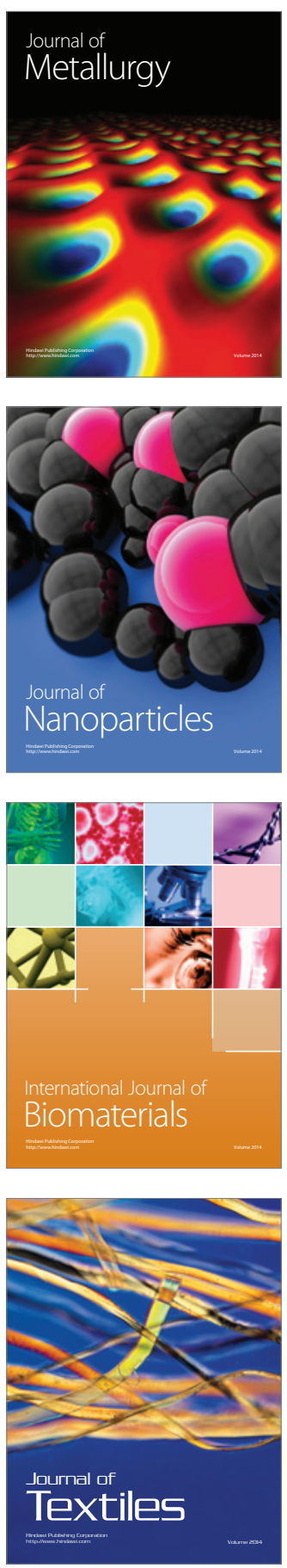